\title{
The lifetime cost estimation of human papillomavirus-related diseases in China: a modeling study
}

\author{
Wenpei Ding ${ }^{1,2^{*}}$, Yue $\mathrm{Ma}^{1,2^{*}}$, Chao $\mathrm{Ma}^{3}$, Daniel C Malone ${ }^{4}$, \\ Aixia Ma ${ }^{1,2}$, Wenxi Tang ${ }^{1,2}$, Lei $\mathrm{Si}^{5}$ \\ ${ }^{1}$ School of International Pharmaceutical Business, China Pharmaceutical University, Nanjing 211198, Jiangsu \\ Province, China; \\ ${ }^{2}$ Center for Pharmacoeconomics and Outcomes Research of China Pharmaceutical University, Nanjing 211198, \\ Jiangsu Province, China; \\ ${ }^{3}$ Department of Economics, School of Economics and Management, Southeast University, Nanjing 211189, \\ Jiangsu Province, China; \\ ${ }^{4}$ Department of Pharmacotherapy, College of Pharmacy, University of Utah, Salt Lake City, UT 84112, USA \\ ${ }^{5}$ The George Institute for Global Health, UNSW Sydney, Sydney, Australia
}

\section{ABSTRACT}

Objectives: To estimate the lifetime treatment costs of patients with human papillomavirus (HPV) infection-related diseases in China and to provide cost estimates for the economic evaluation of HPV intervention strategies. Methods: We extracted real-world hospital data from 2012 to 2019 and screened for subjects who met the criteria of clinical diagnosis of HPV-related diseases to obtain country-specific inputs into a Markov decision model. The model simulated lifetime treatment costs for HPV from the perspective of a national payer. A $5 \%$ discount rate was applied. Costs were converted and inflated to 2020 US dollars (USD) Results: Using 2021 as the base year, the lifetime costs per patient for carcinoma in situ, local metastasis, and distant metastasis cervical cancer are $\$ 24,208(95 \% \mathrm{Cl}: 18,793-30,897)$, $\$ 19,562$ (95\% Cl: 14,456-25,567), and \$17,599 (95\% Cl: 10,604-25,807), respectively. For carcinoma in situ, local metastasis, and distant metastasis vaginal cancer, the lifetime costs are $\$ 17,593$ (95\% Cl: 14,962-23,596), $\$ 17,120$ (95\% Cl: $13,215-22,417)$, and $\$ 22,411(95 \% \mathrm{Cl}$ : 12,172-22,249), respectively. The base-case lifetime cost per patient for different stages of vulvar cancer/penile cancer/anal cancer/oral cancer/oropharyngeal cancer/laryngeal cancer falls within $\$ 17,120-\$ 58,236$. Conclusions: Using real-world data, we calculated lifetime treatment costs of HPV-related cancer in China and found that the lifetime cost for patients exceeded $\$ 17,000$ for various stages of disease. The national burden of HPV-related disease could be significantly reduced by eliminating HPV infection.

Key words: human papillomavirus, economic burden of disease, real-world data

\section{INTRODUCTION}

Approximately 200 genotypes of human papilloma virus (HPV) have been identified to date and are classified into high-risk and low-risk HPVs according to their pathogenicity. The most common highrisk HPVs are HPV 16, 18, 31, 33, 45, 52, and 58 , which are associated with cervical cancer (CC), vaginal cancer $(\mathrm{VaC})$, vulvar cancer (VC), anal cancer (AC), penile cancer (PC), and head-and-neck cancer. Low-risk HPVs variants include HPV 6 and 11, which have been linked to genital warts (GW) and recurrent respiratory papilloma (RRP).$^{[1]}$

HPV-related diseases cause significant burden to society. Among them, CC is the most common disease caused by infection with high-risk HPVs, with its incidence and mortality exhibiting an upward trend throughout China. The standardized incidence of CC increased from 3.06/100,000 in 1988 to $10.7 / 100,000$ in 2018 and the standardized mortality of this disease rose from $1.71 / 100,000$ to 
4.4/100,000 over the same time period. ${ }^{[2]}$ In addition to CC, epidemiological data show that in 2015, high-risk HPV infections caused 1,087 new cases of AC, 1,128 new cases of PC, 694 new cases of VC, 364 new cases of $\mathrm{VaC}$, 462 new cases of oropharyngeal cancer, 2,437 new cases of oral cancer, and 5,903 new cases of laryngeal cancer in China. ${ }^{[3]}$ Low-risk HPV infections of GW reached an incidence of 24.65/100,000. ${ }^{[4]}$ Previous research conducted in China suggests that the cost of hospitalization of CC is significant, approximately US $\$ 4,448$ per patient in Zhejiang Province from 2009 to $2013^{[5]}$ and US $\$ 4,444$ from 2011 to 2016 among tertiary grade A hospitals located in Beijing. ${ }^{[6]}$ In Taiwan of China, the undiscounted lifetime cost (10 years) for patients with CC was US $\$ 15,297$ in $2002 \cdot{ }^{[7]}$ In 2008, a study from Changzhi in Shanxi Province of China showed that the average cost per patient for GW was US $\$ 90$ in Changzhi. ${ }^{[8]}$

China has implemented a relatively complete three-grade prevention strategy for CC (including primary prevention strategies that mainly comprise HPV vaccination, health education, and safe sex practices; secondary prevention strategies that mainly include CC screening and precancerous lesion treatment; and tertiary prevention strategies that mainly involve treatment of invasive (C). However, the current vaccination rate of $\mathrm{HPV}$ is still relatively low ${ }^{[0]}$ due to the low awareness, poor availability, and high price of the vaccines. ${ }^{\left[{ }^{10]}\right.}$ Presently, the approved HPV vaccines in China including Cervarix ${ }^{\circledR}$, Gardasil ${ }^{\circledR} 4$, Gardasi ${ }^{\circledR}$, and Cecolin ${ }^{\circledR}$, which have different protective efficacies according to researches..$^{[11,12]}$ Also, the prices of these four kinds of vaccines are distinctly different. So, to implement national immunization plan according to advice from the World Health Organization (WHO), ${ }^{[13]}$ it is necessary to carry out economic and affordability evaluations of different vaccination strategies (combinations of vaccine valence with the population size and age range for vaccination), thereby choosing the strategy most suitable for national conditions and improving the allocation efficiency of health resources in China.

Because HPV is transmissible, economic evaluation of vaccination strategies requires the use of dynamic models (e.g., transmission dynamics models) to simulate the cost and health benefits for the population at risk. However, owing to a lack of epidemiological investigations and real-world data mining, there are no validated studies on the economic burden of HPV-related diseases in China that can provide cost parameters for research based on the abovementioned models. As a result, only some HPV-related diseases have been included in the existing economic evaluations of $\mathrm{HPV}$ vaccines. For instance, when comparing the cost-effectiveness of different screening and HPV vaccination strategies in China, Levin et al..$^{[14]}$ and Zhang et al..$^{[15]}$ only considered cervical intraepithelial neoplasia (CIN) and CC, whereas Mo et al. ${ }^{[16]}$ only included CIN, CC, and condyloma acuminatum. Owing to the incomplete disease spectrum, the models cannot simulate reality to the greatest extent, which affects the quality and accuracy of the evaluation results and increases the risk of uncertainty in health decision-making.

In this study, we selected representative hospital databases in China and captured a number of HPV-related diseases that met the diagnostic criteria and also had completely qualified data at the same time. Markov models were constructed to predict the lifetime treatment costs (only cost in the hospital because of data source) of HPVrelated conditions, which were then used to estimate the economic burden of HPV-related diseases on a per person basis using national cost inputs. Since few patients suffer from more than one HPV-related disease at the same time and the current economic evaluations only consider single diseases, the lifetime treatment cost of comorbidity was not considered in our study.

\section{METHODS}

\section{Overview}

HPV is known to cause both short-term and long-term diseases. In our study, we included GW and RRP for shortterm HPV-related diseases. Markov models with four to eight health states were constructed to estimate lifetime costs of patients who developed long-term diseases after infection, including CIN, vaginal intraepithelial neoplasia (VaIN), CC, VaC, VC, PC, AC, oral cavity cancer (OcC), oropharynx cancer (OrC), and larynx cancer (LC). The treatment cost per patient over the full course of short-term diseases was taken as the lifetime treatment cost. Transition probabilities were taken from published literature (see Table 1). For short-term conditions such as GW and RRP, the average annual treatment costs were also calculated. To estimate national-level lifetime treatment costs of these diseases, extrapolation of the per person models was made based on the ratio of the medical cost per patient in the source region of disease data to the medical cost per patient for the whole country. The hypotheses of this model were as follows: (1) It is possible for patients with CIN/VaIN to return to the disease-free healthy state, whereas those with other HPV-related diseases cannot return to the diseasefree healthy state and (2) costs in the first-diagnosed year are higher than those in the following years, ${ }^{[17]}$ and the rules could be applied to all the diseases. Figure 1 shows the technical procedures in this study.

\section{Model structure}

According to the natural progression of different diseases, we established a total of eight Markov models consisting 


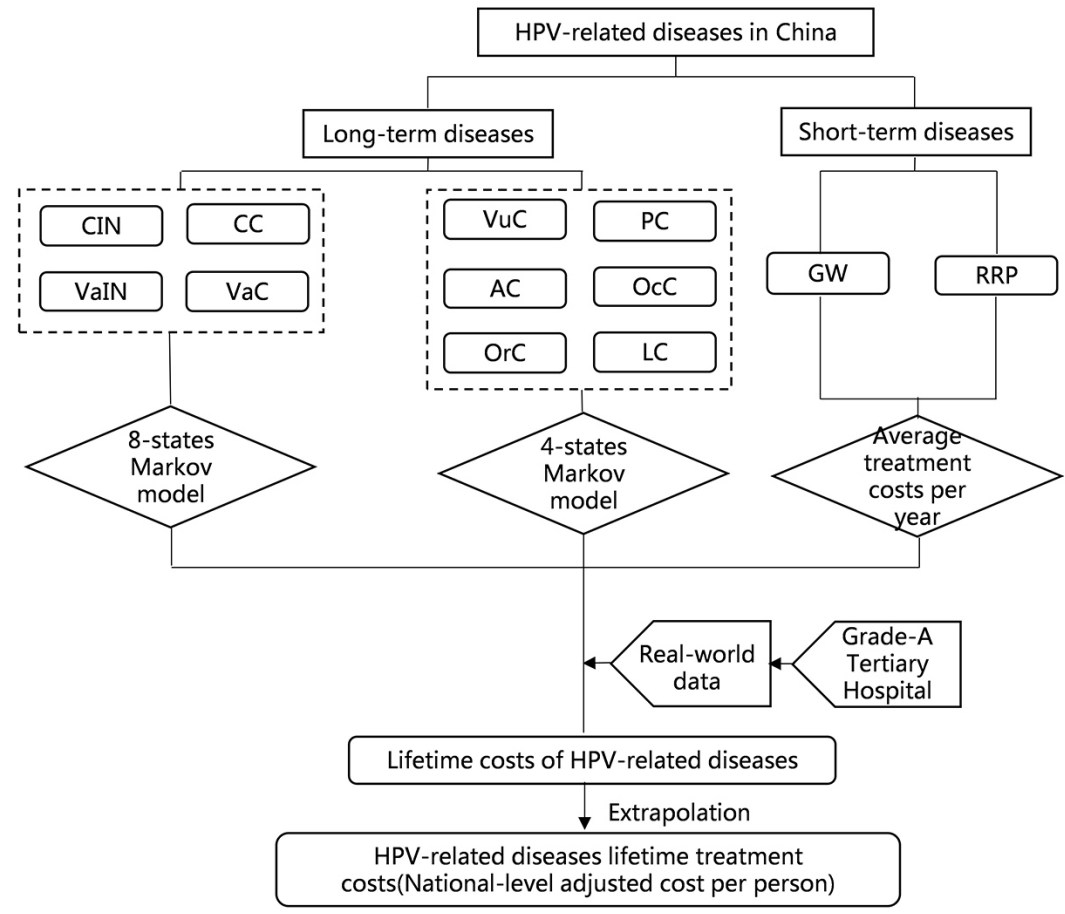

Figure 1: Technology roadmap.CC: cervical cancer; CIN: cervical intraepithelial neoplasia; GW: genital warts; HPV: human papillomavirus; RRP: recurrent respiratory papillomatosis; VaC: vaginal cancer; VaIN: vaginal intraepithelial neoplasia. Other related cancers are anal cancer, larynx cancer, oral cavity cancer, oropharynx cancer, penile cancer, and vulvar cancer.

of 40 health states, and patients in each state received relevant treatments to simulate the lifetime treatment costs of patients with different diseases and in different stages.

Eight-state Markov model: For CC and VaC, precancerous lesions and cancer stage were taken into account ${ }^{[18-21]}$ to construct an eight-state Markov model ${ }^{[22-24]}$ : diseasefree healthy state, grades 1-3 intraepithelial neoplasia, carcinoma in situ (localized cancer), local metastasis (regional cancer), distant metastasis (distant cancer), and death. Because CIN/VaIN are mild diseases compared with $\mathrm{CC} / \mathrm{VC}$, we considered it a disease-free state. It was assumed that among patients with CIN/VaIN, some cases of each grade will be cured to the disease-free healthy state and will have no need of treatment after recovery. Additionally, because some patients may develop CC/VaC when CIN/VaINs progress to grade 3, we included CIN and $\mathrm{CC}$, as well as VaIN and $\mathrm{VaC}$, in the eight-state model.

Four-state Markov model: For the other diseases, precancerous lesions were not considered and only the cancer stage was considered, including carcinoma in situ, local metastasis, distant metastasis, and death; therefore, a four-state Markov model was established. ${ }^{[25-28]}$ The model comprised VC, PC, AC, OC, OrC, and LC. The structure of the constructed models is shown in Figure 2.

The stage settings of "carcinoma in situ, local metastasis, and distant metastasis" for all the abovementioned cancers were obtained in accordance with studies on the progression of related diseases, clinical guidelines, and previously reported transmission dynamics models for HPV. ${ }^{[29,30]}$

Because the follow-up period of patients with GW and RRP in the sample hospital data is less than 1 year and these two diseases can be cured, no model was constructed for the progression of these two diseases and their annual average treatment costs were directly used as the lifetime treatment costs.

For each stage of the target diseases, the population in the start period was set to 1,000 people. The model cycle period was set to 1 year, and the simulation time horizon was lifetime. The model was terminated when the proportion of people alive in the simulation cohort was less than $1 \%$. The annual treatment costs of various diseases per patient were taken as the costs for each period, and the decreasing relationship between the first-diagnosed year and the nonfirst-diagnosed year was also accounted for. We used health system as the research perspective in this study.

\section{Model inputs and data source Real-world data}

The cost data used in this study were derived from teaching hospitals which met with data quality, completeness, 

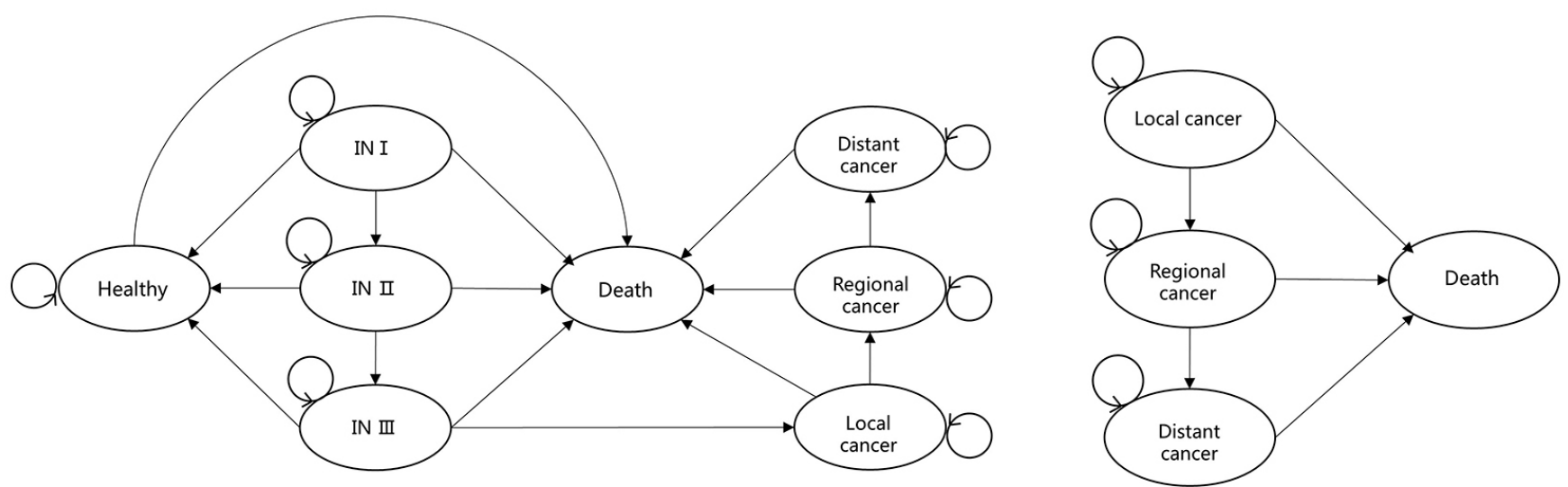

Figure 2: Structure of Markov models. Ovals stand for the health states and arrows stand for the direction of disease progression. Eight-state model involves cervical intraepithelial neoplasia, vaginal intraepithelial neoplasia, cervical cancer and vaginal cancer; four-state model involves vulvar cancer, penile cancer, anal cancer, oral cavity cancer, oropharynx cancer, and larynx cancer. IN1-3: grades 1-3 cervical/vaginal intraepithelial neoplasia. Localized/regional/distant cancer: corresponding to carcinoma in situ/local metastasis/distant metastasis stage for a specific HPV-related cancer.

and availability. The source hospital and time range of the data, sample size $\square$ together with the corresponding disease stage are listed in Table S1. The specific method of data acquisition was as follows: first, we defined the diagnosis name, English abbreviation, and International Statistical Classification of Diseases and Related Health Problems (ICD) code-10 of the diseases and constructed the rules using logical words; then, we captured patient data for specific stages of the target diseases from the hospital database using artificial intelligence. Descriptive statistics were performed to estimate the cost by disease stage.

\section{Basic parameters and assumptions}

The initial cohort number was set as 1,000 for each simulation, and the initial cohort age for each health state was equal to the average age calculated from real-word data of corresponding diseases. In addition, the simulation of each disease was stopped when more than $99 \%$ people in the initial cohort were dead.

\section{Average annual treatment cost}

The cost parameters of all the remaining health states included the average annual treatment cost for each patient in these states. The average annual treatment cost included outpatient and inpatient costs. To simulate the lifelong costs, we distinguished the costs in the first-diagnosed year and in the subsequent year. Also, we assumed that the costs in the first-diagnosed year were higher than in the follow-up visits. The first-diagnosed cost refers to the treatment cost for a patient in the year of the first medical visit, whereas the non-first-diagnosed cost refers to the average annual treatment cost for a patient in the course of follow-up treatment. For a certain disease stage, the first-diagnosed cost was used for the model to simulate the first cycle of the disease stage and the non-first-diagnosed cost to simulate the remaining cycles.

Owing to the limited sample size, the first-diagnosed cost was calculated from available data only for the following six disease stages: grade $1 \mathrm{CIN}$, carcinoma in situ of CC, local metastasis of CC, distant metastasis of CC, carcinoma in situ of VC, and carcinoma in situ of LC. For the remaining disease stages with no first-diagnosis data being traced, we performed linear fitting on the first-diagnosed cost and non-first-diagnosed cost of the six disease stages with available data (the fitting function is shown in Figure S1). ${ }^{[31,32]}$ This yielded the proportional coefficient, 1.1567, between first-diagnosed and non-first-diagnosed costs. Assuming that this coefficient applies to all diseases, we inferred the average annual first-diagnosed cost of the disease stages that lacked first-diagnosis data.

\section{Transition probability}

The transition probabilities involved in the eight Markov models included the probability of CIN/VaIN transitioning from various grades to the healthy state, the probability of various diseases transitioning from low to high stages, the probability of transitioning from a noncancerous state to death (background mortality), and the probability of transitioning from a cancerous state to death. Most of these probability parameters were derived from the published literature (see Table 1) and follow the following principles: (1) the same model state setting as in this study; (2) domestic sources are preferred if there are domestic data sources; (3) the mortality rate of certain states is converted from the survival rate of published literature or clinical guidelines; and (4) for diseases with few published studies, the transition probabilities were estimated using similar diseases based on recommendations from key clinical opinion leaders. The parameter sources are 
Ding et al.: HPV lifetime cost

\begin{tabular}{|c|c|c|c|}
\hline Input parameters & Mean & Stand error ${ }^{\ddagger}$ & Source \\
\hline \multicolumn{4}{|l|}{ Cost } \\
\hline CIN $1^{*}$ & 366 & 85.6 & Hospital databases \\
\hline CIN2* & 819 & 40.2 & Hospital databases + estimated increase \\
\hline CIN3 $^{*}$ & 1,096 & 37.9 & \\
\hline $\mathrm{CCl}^{*}$ & 10,051 & 649.5 & Hospital databases \\
\hline $\mathrm{CCr}^{*}$ & 11,251 & 889.2 & \\
\hline $\mathrm{CCd}^{*}$ & 11,813 & $1,180.9$ & \\
\hline $\mathrm{CIN} 1^{\dagger}$ & 422 & 33.3 & Hospital databases + estimated increase \\
\hline $\mathrm{CIN}^{\dagger}$ & 708 & 34.8 & \\
\hline $\mathrm{CIN}^{+}$ & 947 & 32.8 & \\
\hline $\mathrm{CCl}+$ & 6,952 & 618.6 & \\
\hline $\mathrm{CCr}^{\dagger}$ & 6,960 & 899.3 & \\
\hline $\mathrm{CCd}^{\dagger}$ & 11,348 & $2,002.1$ & \\
\hline ValN1* & 3,262 & 423.7 & \\
\hline ValN2* & 3,038 & 391.5 & \\
\hline ValN3* & 1,555 & 139.8 & \\
\hline $\mathrm{VaCl}^{*}$ & 4,576 & 387.4 & \\
\hline $\mathrm{VaCr}^{*}$ & 5,940 & 628.1 & \\
\hline $\mathrm{VaCd}^{*}$ & 7,749 & $1,306.5$ & \\
\hline ValN1 ${ }^{\dagger}$ & 2,820 & 366.3 & \\
\hline ValN2 $^{+}$ & 2,626 & 338.5 & \\
\hline ValN3 $^{\dagger}$ & 1,344 & 120.9 & \\
\hline $\mathrm{VaCl}^{\dagger}$ & 3,956 & 334.9 & \\
\hline $\mathrm{VaC}^{\mathrm{rt}}$ & 5,135 & 543.0 & \\
\hline $\mathrm{VaCd}^{\dagger}$ & 6,700 & $1,129.5$ & \\
\hline $\mathrm{VuCl}^{*}$ & 5,236 & 517.4 & Hospital databases \\
\hline $\mathrm{VuCr}^{*}$ & 6,944 & 532.5 & Hospital databases + estimated increase \\
\hline $\mathrm{VuCd}^{*}$ & 8,296 & $1,058.3$ & \\
\hline $\mathrm{VuCl}^{\dagger}$ & 3,402 & 508.7 & \\
\hline $\mathrm{VuCr}^{\dagger}$ & 6,004 & 460.3 & \\
\hline $\mathrm{VuCd}^{\dagger}$ & 7,172 & 914.9 & \\
\hline $\mathrm{PCl}^{*}$ & 7,040 & 487.4 & \\
\hline $\mathrm{PCr}^{*}$ & 10,385 & 680.2 & \\
\hline $\mathrm{PCd}^{*}$ & 13,189 & $1,604.8$ & \\
\hline $\mathrm{PCl}^{\dagger}$ & 6,087 & 421.4 & \\
\hline $\mathrm{PCr}^{\dagger}$ & 8,978 & 588.1 & \\
\hline $\mathrm{PCd}^{\dagger}$ & 11,402 & $1,387.4$ & \\
\hline $\mathrm{ACl}^{*}$ & 7,846 & 760.7 & \\
\hline $\mathrm{ACr}^{*}$ & 10,324 & 973.4 & \\
\hline $\mathrm{ACd}^{*}$ & 14,076 & $1,646.2$ & \\
\hline $\mathrm{ACl}^{\dagger}$ & 6,783 & 657.6 & \\
\hline $\mathrm{ACr}^{\dagger}$ & 8,925 & 841.5 & \\
\hline $\mathrm{ACd}^{\dagger}$ & 12,169 & $1,423.2$ & \\
\hline $\mathrm{OcCl}^{*}$ & 5,526 & 361.6 & \\
\hline $\mathrm{OcCr}^{*}$ & 7,918 & 527.9 & \\
\hline $\mathrm{OcCd}^{*}$ & 10,653 & $1,141.1$ & \\
\hline $\mathrm{OcCl}^{\dagger}$ & 4,777 & 312.6 & \\
\hline $\mathrm{OcCr}^{\dagger}$ & 6,845 & 456.4 & \\
\hline $\mathrm{OcCd}^{\dagger}$ & 9,210 & 986.5 & \\
\hline $\mathrm{OrCl}^{*}$ & 6,644 & 589.8 & \\
\hline $\mathrm{OrCr}^{*}$ & 9,188 & 783.0 & \\
\hline $\mathrm{OrCd}^{*}$ & 12,162 & $1,394.5$ & \\
\hline $\mathrm{OrCl}^{\dagger}$ & 5,744 & 509.9 & \\
\hline $\mathrm{OrCr}^{\dagger}$ & 7,943 & 676.9 & \\
\hline $\mathrm{OrCd}^{+}$ & 10,514 & $1,205.6$ & \\
\hline $\mathrm{LCl}^{*}$ & 17,426 & $4,033.5$ & Hospital databases \\
\hline $\mathrm{LCr}^{*}$ & 8,702 & 435.3 & Hospital databases + estimated increase \\
\hline $\mathrm{LCd}^{*}$ & 10,301 & 716.2 & \\
\hline $\mathrm{LCl}^{\dagger}$ & 12,696 & $1,705.4$ & \\
\hline $\mathrm{LCr}^{\dagger}$ & 7,523 & 376.4 & \\
\hline $\mathrm{LCd}^{\dagger}$ & 8,905 & 619.2 & \\
\hline
\end{tabular}


Ding et al.: HPV lifetime cost

\begin{tabular}{|c|c|c|c|}
\hline Input parameters & Mean & Stand error ${ }^{\ddagger}$ & Source \\
\hline \multicolumn{4}{|l|}{ Transition probabilities } \\
\hline CIN1 to health & 0.230 & 0.057 & [33] \\
\hline CIN2 to health & 0.315 & 0.061 & \\
\hline CIN3 to health & 0.004 & 0.027 & [34] \\
\hline CIN1 to CIN2 & 0.031 & 0.012 & [33] \\
\hline CIN2 to CIN3 & 0.193 & 0.058 & \\
\hline CIN3 to $\mathrm{CCl}$ & 0.152 & 0.027 & [34] \\
\hline $\mathrm{CCl}$ to $\mathrm{CCr}$ & 0.239 & 0.062 & \\
\hline $\mathrm{CCr}$ to $\mathrm{CCd}$ & 0.547 & 0.113 & \\
\hline $\mathrm{CCl}$ to death & 0.223 & 0.062 & [35] \\
\hline $\mathrm{CCr}$ to death & 0.453 & 0.110 & \\
\hline CCd to death & 0.588 & 0.113 & \\
\hline ValN1 to health & 0.230 & 0.057 & [33] \\
\hline ValN2 to health & 0.315 & 0.061 & \\
\hline ValN3 to health & 0.004 & 0.027 & [34] \\
\hline ValN1 to ValN2 & 0.031 & 0.012 & [33] \\
\hline ValN2 to ValN3 & 0.193 & 0.058 & \\
\hline ValN3 to $\mathrm{VaCl}$ & 0.070 & 0.015 & [36] \\
\hline $\mathrm{VaCl}$ to $\mathrm{VaCr}$ & 0.239 & 0.062 & [34] \\
\hline $\mathrm{VaCr}$ to $\mathrm{VaCd}$ & 0.496 & 0.113 & \\
\hline $\mathrm{VaCl}$ to death & 0.288 & 0.059 & [37] \\
\hline $\mathrm{VaCr}$ to death & 0.504 & 0.109 & \\
\hline VaCd to death & 0.632 & 0.056 & \\
\hline $\mathrm{VuCl}$ to $\mathrm{VuCr}$ & 0.239 & 0.062 & [34] \\
\hline VuCr to $\mathrm{VuCd}$ & 0.547 & 0.113 & \\
\hline $\mathrm{VuCl}$ to death & 0.223 & 0.062 & [35] \\
\hline VuCr to death & 0.453 & 0.110 & \\
\hline VuCd to death & 0.588 & 0.113 & \\
\hline $\mathrm{PCl}$ to $\mathrm{PCr}$ & 0.210 & 0.061 & [38] \\
\hline $\mathrm{PCr}$ to $\mathrm{PCd}$ & 0.547 & 0.113 & [34] \\
\hline $\mathrm{PCl}$ to death & 0.223 & 0.062 & [35] \\
\hline $\mathrm{PCr}$ to death & 0.453 & 0.110 & \\
\hline PCd to death & 0.588 & 0.113 & \\
\hline $\mathrm{ACl}$ to $\mathrm{ACr}$ & 0.239 & 0.062 & [34] \\
\hline $\mathrm{ACr}$ to $\mathrm{ACd}$ & 0.500 & 0.090 & [39] \\
\hline $\mathrm{ACl}$ to death & 0.181 & 0.060 & [40] \\
\hline $\mathrm{ACr}$ to death & 0.330 & 0.080 & \\
\hline ACd to death & 0.501 & 0.087 & \\
\hline $\mathrm{OcCl}$ to $\mathrm{OcCr}$ & 0.239 & 0.062 & [34] \\
\hline $\mathrm{OcCr}$ to $\mathrm{OcCd}$ & 0.547 & 0.113 & \\
\hline OcCl to death & 0.307 & 0.055 & [41] \\
\hline OcCr to death & 0.453 & 0.110 & [35] \\
\hline OcCd to death & 0.588 & 0.113 & \\
\hline $\mathrm{OrCl}$ to $\mathrm{OrCr}$ & 0.239 & 0.062 & [34] \\
\hline $\mathrm{OrCr}$ to $\mathrm{OrCd}$ & 0.547 & 0.113 & \\
\hline $\mathrm{OrCl}$ to death & 0.163 & 0.084 & [42] \\
\hline OrCr to death & 0.163 & 0.084 & \\
\hline OrCd to death & 0.408 & 0.108 & \\
\hline $\mathrm{LCl}$ to $\mathrm{LCr}$ & 0.239 & 0.062 & [34] \\
\hline $\mathrm{LCr}$ to $\mathrm{LCd}$ & 0.547 & 0.113 & \\
\hline $\mathrm{LCI}$ to death & 0.223 & 0.062 & [35] \\
\hline LCr to death & 0.453 & 0.110 & \\
\hline LCd to death & 0.588 & 0.113 & \\
\hline Background mortality & 0.056 & 0.023 & [43] \\
\hline
\end{tabular}

AC: anal cancer; CC: cervical cancer; CIN: cervical intraepithelial neoplasia; d: distant; I: localized; LC: larynx cancer; OcC: oral cavity cancer; OrC: oropharynx cancer; PC: penile cancer; r: regional; VaC: vaginal cancer; ValN: vaginal intraepithelial neoplasia; VuC: vulvar cancer.

${ }^{*}$ First diagnosis. ${ }^{\dagger}$ Non-first diagnosis; estimated increases in progressed stage were simulated using linear fitted model. Refer to Figure $\mathrm{S} 1$ for model information. ${ }^{ \pm}$Standard errors were calculated from 1,000 times random sampling from $\pm 20 \%$ around the mean values. 

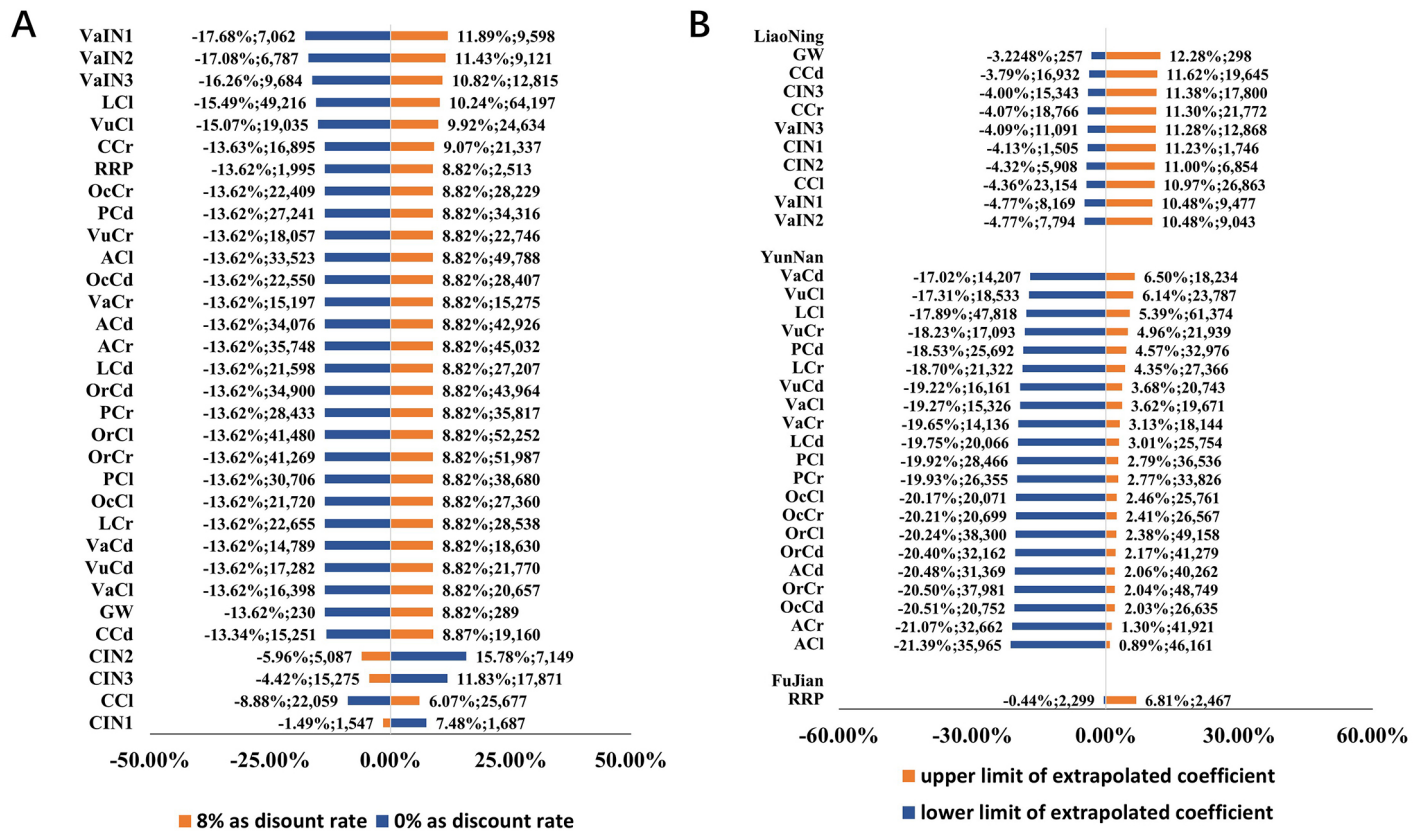

Figure 3: Results of univariate uncertainty analysis. AC: anal cancer; CC: cervical cancer; CIN: cervical intraepithelial neoplasia; d: distant; GW: genital warts; I: localized; LC: larynx cancer; OcC: oral cavity cancer; OrC: oropharynx cancer; PC: penile cancer; r: regional; RRP: recurrent respiratory papillomatosis; ValN: Vaginal intraepithelial neoplasia; VaC: vaginal cancer; VuC: vulvar cancer.

summarized in Table 1. The cost parameters and standard errors are listed in Table 1.

\section{Cost extrapolation}

Because the micro-treatment costs for diseases were only derived from hospitals in a single province and city, we extrapolated them to the national-level adjusted per person cost. According to the method published by Liu et al. ${ }^{[44]}$ for calculating the national average cost using regional data, we assumed that the difference in the medical cost of all diseases between regions is also applicable to single diseases and constructed a regional coefficient for linear extrapolation. Further details are available in Table S2.

\section{Discounting and currency conversion}

In this study, we first adjusted the historical data (20172019) in the hospital database to the year 2021 (baseline year of the Markov model) and then discounted future costs to 2021 using a discount rate of $5 \%$. All costs were converted into USD using the current exchange rate in 2020: 1 Chinese yuan $(\mathrm{CNY})=$ US $\$ 0.1524 .{ }^{[45]}$

\section{Uncertainty analysis Monte Carlo simulation}

The second-order Monte Carlo simulation with 10,000 iterations was used to simulate the influence of randomly distributed parameters that included costs, transition probabilities, and mortality rates. We assumed that the costs conformed to the gamma distribution, and the transition probability and mortality rates conformed to the beta distribution. The standard errors of cost parameters came from the results of hospital data analysis. For some inputs, including transition probabilities and mortality estimates, there was no standard error available; thus, we randomly sampled 1,000 times from $\pm 20 \%$ around the mean values and obtained the standard error from simulation. Standard errors for cost, transition probabilities, and mortality rates are shown in Table 1.

\section{Univariate sensitivity analysis}

We used univariate sensitivity analysis to explore the influences on non-randomly distributed uncertain parameters. Discount rate was assumed to be varied in the range of $0 \%-8 \%{ }^{[46]}$ Extrapolation coefficients were assumed to be varied according to the upper and lower limits of model estimates. Results of univariate sensitivity analysis are presented in Figure 3.

\section{RESULTS}

\section{Base-case results}

Table 2 summarizes the life expectancies, disease-related lifetime costs simulated based on the Markov model, and the disease-related lifetime costs extrapolated to the whole country.

The lifetime costs per patient for carcinoma in situ, local metastasis, and distant metastasis CC are $\$ 26,174$, $\$ 21,214$, and $\$ 19,141$, respectively. For carcinoma in situ, 


\begin{tabular}{|c|c|c|c|c|c|c|c|c|c|}
\hline \multirow[t]{3}{*}{ Diseases } & \multicolumn{3}{|c|}{ Base-case analysis } & \multicolumn{6}{|c|}{ Uncertainty analysis $^{*}$} \\
\hline & \multirow[t]{2}{*}{ Life years $^{\dagger}$} & \multirow[t]{2}{*}{$\begin{array}{l}\text { Markov } \\
\text { model }\end{array}$} & \multirow{2}{*}{$\begin{array}{l}\text { National-level } \\
\text { adjusted per } \\
\text { person cost }\end{array}$} & \multicolumn{3}{|c|}{ MC simulation } & \multicolumn{3}{|c|}{$\begin{array}{l}\text { National-level adjusted per person } \\
\text { cost }\end{array}$} \\
\hline & & & & Mean & $\begin{array}{l}95 \% \mathrm{Cl} \\
\text { lower }\end{array}$ & $\begin{array}{l}95 \% \mathrm{Cl} \\
\text { upper }\end{array}$ & Mean & $\begin{array}{l}95 \% \mathrm{Cl} \\
\text { lower }\end{array}$ & $\begin{array}{l}95 \% \mathrm{Cl} \\
\text { upper }\end{array}$ \\
\hline \multicolumn{10}{|c|}{ Long-term diseases } \\
\hline CIN1 & $>60$ & 1,702 & 1,570 & 1,765 & 956 & 2,575 & 1,629 & 882 & 2,376 \\
\hline CIN2 & 56 & 6,679 & 6,175 & 6,857 & 3,723 & 9,992 & 6,340 & 3,442 & 9,238 \\
\hline CIN3 & 56 & 17,344 & 15,981 & 17,831 & 12,423 & 23,239 & 16,430 & 11,447 & 21,413 \\
\hline $\mathrm{CCl}$ & 14 & 26,174 & 24,208 & 26,863 & 20,320 & 33,406 & 24,845 & 18,793 & 30,897 \\
\hline $\mathrm{CCr}$ & 8 & 21,214 & 19,562 & 21,702 & 15,677 & 27,726 & 20,012 & 14,456 & 25,567 \\
\hline $\mathrm{CCd}$ & 7 & 19,141 & 17,599 & 19,801 & 11,533 & 28,069 & 18,206 & 10,604 & 25,807 \\
\hline ValN1 & $>60$ & 9,234 & 8,578 & 9,504 & 5,968 & 13,040 & 8,828 & 5,543 & 12,113 \\
\hline ValN2 & $>60$ & 8,811 & 8,185 & 8,993 & 6,263 & 11,722 & 8,354 & 5,818 & 10,889 \\
\hline ValN3 & 41 & 12,538 & 11,564 & 12,913 & 9,023 & 16,802 & 11,909 & 8,322 & 15,496 \\
\hline $\mathrm{VaCl}$ & 8 & 12,260 & 18,984 & 12,451 & 9,663 & 15,238 & 19,279 & 14,962 & 23,596 \\
\hline $\mathrm{VaCr}$ & 8 & 11,308 & 17,593 & 11,451 & 8,494 & 14,409 & 17,816 & 13,215 & 22,417 \\
\hline $\mathrm{VaCd}$ & 7 & 11,364 & 17,120 & 11,424 & 8,080 & 14,768 & 17,210 & 12,172 & 22,249 \\
\hline $\mathrm{VuCl}$ & 10 & 14,825 & 22,411 & 14,821 & 12,645 & 16,997 & 22,405 & 19,116 & 25,694 \\
\hline $\mathrm{VuCr}$ & 9 & 13,673 & 20,902 & 13,674 & 10,740 & 16,609 & 20,905 & 16,418 & 25,391 \\
\hline VuCd & 6 & 12,928 & 20,006 & 12,921 & 9,534 & 16,308 & 19,995 & 14,754 & 25,237 \\
\hline $\mathrm{PCl}$ & 10 & 22,771 & 35,546 & 23,346 & 17,119 & 29,573 & 36,444 & 26,723 & 46,164 \\
\hline $\mathrm{PCr}$ & 9 & 21,082 & 32,915 & 21,597 & 15,478 & 27,715 & 33,718 & 24,165 & 43,271 \\
\hline $\mathrm{PCd}$ & 8 & 20,552 & 31,535 & 21,146 & 12,866 & 29,427 & 32,447 & 19,741 & 45,153 \\
\hline $\mathrm{ACl}$ & 12 & 28,770 & 45,754 & 29,410 & 21,540 & 37,280 & 46,771 & 34,255 & 59,288 \\
\hline $\mathrm{ACr}$ & 11 & 26,127 & 41,382 & 26,641 & 19,730 & 33,551 & 42,195 & 31,250 & 53,140 \\
\hline $\mathrm{ACd}$ & 10 & 25,093 & 39,447 & 25,620 & 16,943 & 34,297 & 40,276 & 26,635 & 53,917 \\
\hline $\mathrm{OcCl}$ & 11 & 16,055 & 25,143 & 16,332 & 12,675 & 19,988 & 25,576 & 19,850 & 31,302 \\
\hline $\mathrm{OcCr}$ & 9 & 16,558 & 25,941 & 16,982 & 12,170 & 21,794 & 26,605 & 19,066 & 34,144 \\
\hline $\mathrm{OcCd}$ & 8 & 16,600 & 26,104 & 17,173 & 10,587 & 23,760 & 27,006 & 16,648 & 37,363 \\
\hline $\mathrm{OrCl}$ & 13 & 30,638 & 48,018 & 32,060 & 19,891 & 44,228 & 50,247 & 31,175 & 69,318 \\
\hline $\mathrm{OrCr}$ & 10 & 30,382 & 47,773 & 31,627 & 20,397 & 42,856 & 49,731 & 32,073 & 67,388 \\
\hline OrCd & 9 & 25,727 & 40,401 & 26,926 & 14,013 & 39,839 & 42,284 & 22,006 & 62,562 \\
\hline $\mathrm{LCl}$ & 10 & 38,251 & 58,236 & 39,145 & 26,393 & 51,897 & 59,597 & 40,183 & 79,012 \\
\hline $\mathrm{LCr}$ & 9 & 17,056 & 26,226 & 17,493 & 12,855 & 22,131 & 26,898 & 19,767 & 34,030 \\
\hline $\mathrm{LCd}$ & 8 & 16,051 & 25,002 & 16,531 & 10,501 & 22,560 & 25,750 & 16,358 & 35,142 \\
\hline \multicolumn{10}{|c|}{ Short-term diseases } \\
\hline GW & I & 291 & 266 & I & I & I & 266 & 235 & 296 \\
\hline RRP & 1 & 2,292 & 2,309 & 1 & 1 & 1 & 2,309 & 2,001 & 2,618 \\
\hline
\end{tabular}

AC: anal cancer; CC: cervical cancer; CIN: cervical intraepithelial neoplasia; d: distant; GW: genital warts; I, localized; LC: larynx cancer; OcC: oral cavity cancer; OrC: oropharynx cancer; PC: penile cancer; r: regional; RRP: recurrent respiratory papillomatosis; VaIN: vaginal intraepithelial neoplasia; VaC: vaginal cancer; VuC: vulvar cancer.

*Uncertain parameters include costs from sampled hospital data, transition probabilities, and mortality rates.

${ }^{\dagger}$ Number of model cycles when simulated cohorts dead more than $99 \%$; /: no simulation.

local metastasis, and distant metastasis $\mathrm{VaC}$, the lifetime costs are $\$ 12,260, \$ 11,308$, and $\$ 11,364$, respectively. The base-case lifetime cost per patient for carcinoma in situ, local metastasis, and distant metastasis $\mathrm{VuC} / \mathrm{PC} / \mathrm{AC} /$ OcC/OrC/LC are $\$ 14,825, \$ 13,673, \$ 12,928 / \$ 22,771$, $\$ 21,082, \$ 20,552 ; \$ 28,770, \$ 26,127, \$ 25,093 / \$ 16,055$, $\$ 16,558, \$ 16,600$; and $\$ 30,638, \$ 30,382, \$ 25,727 / \$ 38,251$, $\$ 17,056$, and $\$ 16,051$, respectively. For CIN1-3 and VaIN1-3, the lifetime costs are $\$ 1,702, \$ 6,679, \$ 17,344$ and $\$ 9,234, \$ 8,811, \$ 12,538$, respectively. The base-case lifetime cost per patient for GW and RRP are \$291 and $\$ 2,292$, respectively.

After extrapolating the above results to national-level adjusted per person cost, the lifetime costs per patient for carcinoma in situ, local metastasis, and distant metastasis CC are $\$ 24,208, \$ 19,562$, and $\$ 17,599$, respectively. For carcinoma in situ, local metastasis, and distant metastasis $\mathrm{VaC}$, the lifetime costs are $\$ 18,984, \$ 17,593$, and $\$ 17,120$, respectively. The base-case lifetime cost per patient for 
carcinoma in situ, local metastasis, and distant metastasis $\mathrm{VuC} / \mathrm{PC} / \mathrm{AC} / \mathrm{OcC} / \mathrm{OrC} / \mathrm{LC}$ are $\$ 22,411, \$ 20,902$, $\$ 20,006 / \$ 35,546, \$ 32,915, \$ 31,535 ; \$ 45,754, \$ 41,382$, $\$ 39,447 / \$ 25,143, \$ 25,941, \$ 26,104$; and $\$ 48,018, \$ 47,773$, $\$ 40,401 / \$ 58,236, \$ 26,226$, and $\$ 25,002$, respectively. For CIN1-3 and VaIN1-3, the lifetime costs are $\$ 1,570, \$ 6,175$, $\$ 15,981$ and $\$ 8,578, \$ 8,185, \$ 11,564$, respectively. The base-case lifetime costs per patient for GW and RRP are $\$ 266$ and $\$ 2,309$, respectively.

\section{Uncertainty analysis}

Results from Monte Carlo simulation are also presented in Table 2. The median, maximum, and minimum values of the extrapolated costs are summarized in Table S3.

Results from univariate sensitivity analysis are shown in Figure 3. Lifetime cost of VaIN1 is most sensitive to the change of discount rate and that of CIN1 the least sensitive. Lifetime costs of diseases extrapolated from Yunnan province are majorly more uncertain from other two provinces.

\section{DISCUSSION}

\section{Main findings}

In this study, the lifetime treatment costs of $\mathrm{LC}$, OrC, $\mathrm{AC}, \mathrm{CC}, \mathrm{VC}, \mathrm{PC}$, and $\mathrm{VaC}$ were higher (from $\$ 17,120$ to $\$ 58,236)$ as compared to the costs of CIN/VaIN, RRP, and GW (from $\$ 266$ to $\$ 15,981$ ). This result is consistent with the logic that the greater the disease severity and the longer the disease course, the higher the treatment cost. It should be pointed out that although the lifetime treatment cost of $\mathrm{CC}$ was not at the highest level, the incidence of CC was the highest compared with the other diseases. ${ }^{[47]}$ Moreover, according to the physiological and pathological processes of cervical malignant tumor progression, nearly all CCs are related to HPV. ${ }^{[48-50]}$ Therefore, overall, the economic burden of CC was heaviest among the HPV-related diseases evaluated in this study. We also compared the above result with those of existing studies.

From the limited studies evaluating the burden of HPV-related diseases in China, we found that only $\mathrm{Hu}$ and Goldie ${ }^{[51]}$ reported both point estimates and ranges for primary HPV-related conditions. Although it was published in 2008, the rank order of expenditures for various conditions is similar to our study. For example, their study findings showed that $\mathrm{OrC}$ has the highest lifetime treatment cost, followed by $\mathrm{AC}, \mathrm{VaC}, \mathrm{VC}$, and $\mathrm{PC}$; the lifetime treatment cost of GW is the lowest.

Our results also showed that the average annual treatment costs per patient of CIN/VaIN caused by HPV exhibited an increasing trend with increasing lesion grade; that is, the more serious the intraepithelial neoplasia, the higher the lifetime treatment cost. In contrast, the costs of HPVrelated cancers exhibited a decreasing trend with increasing disease stage; the treatment cost of carcinoma in situ was the highest, whereas the treatment costs of local and distant metastases decreased successively. This trend is relatively in line with the real-world cancer treatment model. Patients with early carcinoma in situ have a long survival period and require long-term maintenance treatment, resulting in relatively high lifetime costs. In contrast, patients with advanced metastatic cancer have a short survival period and even more complex treatment methods, such as surgery combined with chemoradiotherapy, which will lead to relatively low lifetime treatment costs. This trend of lifetime costs is similar to that in previously reported studies on disease burden. For instance, in a study involving older patients with AC in the USA, Deshmukh et al. ${ }^{[2]}$ found that the average lifetime treatment costs of $\mathrm{AC}$ stages III and IV were US \$93,291 and US \$73,178 for male patients and US $\$ 78,039$ and US $\$ 63,276$ for female patients, respectively. This result indicates that as disease severity becomes greater, the lifetime treatment cost first increases and then decreases.

Among the lifetime treatment costs of the diseases simulated in this study, although grade 1 CIN/VaIN belongs to the same grade as precancerous lesions, the lifetime treatment cost of the former disease (US \$1,629) was considerably lower than that of the latter disease (US $\$ 8,828)$. Combined with the data of individual patients, we found that patients with VaIN grade 1 had a lower average annual number of outpatient visits, but a higher number of inpatient visits; in other words, most patients with VaIN grade 1 must be hospitalized owing to severe symptoms. Accordingly, we speculate that this result may be related to implementation of the CC screening program in China. ${ }^{[53,54]}$ This program targets Chinese women of the appropriate age to detect patients with early CIN in a timely manner and prompt patients with mild disease to seek medical treatment as early as possible; as a result, patients consume fewer medical resources and bear lower treatment costs. ${ }^{[55]}$

\section{Applications of lifetime treatment costs}

There have been four kinds of HPV vaccines approved in China against two, four, or nine kinds of viruses from HPV$6,11,18,31,33,45,52$, and 58 with different efficacies and costs of protecting HPV-related diseases mentioned in our study. So, how to choose the most cost-effective HPV vaccination strategy and make relevant public health policies is an important question that cannot be ignored by health policy makers in China. Accordingly, we provide a comprehensive estimate of the lifetime costs of HPV-related diseases in China, which are very necessary 
for the dynamic transmission model used for economic evaluation of HPV vaccination strategies. The results of these economic evaluations will be supportive evidences to support HPV vaccination strategies. And finally, the allocation of health resources in China will be optimized.

Based on these lifetime treatment costs, researchers can also estimate the disease burden of HPV-related diseases in China, even in other developing countries, combined with corresponding epidemiological data. The disease burden can be used to compare with average per capita income of China to explore the extent of burden of HPV-related diseases in the Chinese society and to support HPV-related vaccination strategy and the policy controlling these diseases.

\section{Strengths and limitations}

First, this study systematically estimated the lifetime treatment costs of patients with HPV-related diseases in China using quantitative analysis. Other studies have not reported the results of all HPV-related diseases ${ }^{[56]}$ or considered the stages. ${ }^{[0]}$ Second, based on real-world data, we simulated long-term lifetime treatment costs instead of replacing them with short-term ones, which may lead to underestimation of the lifetime treatment cost for economic evaluations using a transmission dynamics model. For example, Karen et al..$^{[57]}$ and Zou et al. ${ }^{[5]}$ only reported the costs of various items and total cost, but not the lifetime treatment cost of CC when evaluating the cost-effectiveness of HPV vaccination strategies in China. Third, real-world data can also represent the treatment costs of Chinese patients, and thereby better support decisionmaking in China, corresponding to the recommendations of the Chinese Pharmacoeconomics Evaluation Guide 2020 and the International Society for Pharmacoeconomics and Outcomes Research (ISPOR ${ }^{[46,59]}$ for priority use of local data in decision-affected regions. Therefore, the economic evaluations of HPV vaccination strategies in China by Song et al. ${ }^{[60]}$ and $\mathrm{Ma}$ et al. ${ }^{[61]}$ based on data from other counties are unsuitable. Finally, we considered the differences in economic level among various regions of China ${ }^{[44]}$ and obtained the national-level adjusted per person lifetime treatment costs of HPV-related diseases, which can strongly support national-level decision-making. ${ }^{[62,63]}$

Inevitably, this study still has certain limitations. With regard to the methods, for the transmission probabilities and their standard errors or deviations and the first-diagnosed treatment costs which cannot be obtained from the published literature or existing data, we referred to similar diseases, fitting, or assumptions; for the extrapolation costs of the whole country, we used a simple linear extrapolation method. These references and assumptions increase the uncertainty of the study results to a certain extent. With regard to the sample data, they were all from hospital databases lacking channels to trace the out-of-hospital treatment costs of patients, and not all target diseases correspond to the samples are caused by HPV, which may lead to bias of the results. Hu et al. ${ }^{[51]}$ only assumed the proportion of HPV-caused diseases of the overall patients when estimating the lifetime costs of HPV-related diseases. The possible reason is that for the same disease, whether or not caused by HPV, the treatment methods are similar and have little influence on the differences in treatment costs.

In recent years, the health care system in China has attached increasing importance to the construction of data platforms and has also paid increasing attention to real-world evidence. ${ }^{[64,65]}$ If researchers can collect more comprehensive treatment cost data with HPV-related diseases in China, the results of our study can be externally verified to ensure that the bias is within an acceptable range.

\section{CONCLUSIONS}

The lifetime costs per patient for carcinoma in situ, local metastasis, and distant metastasis CC are $\$ 24,208, \$ 19,562$, and $\$ 17,599$, respectively. Lifetime costs for other HPVrelated diseases in China vary from $\$ 266(\mathrm{GW})$ to $\$ 58,236$ (carcinoma in situ LC). Based on real-world data from the public hospitals in China, the findings of this study fill in the gap in the literature regarding the life treatment costs of patients with HPV-related diseases in the country using data analysis, model simulation, and linear extrapolation. The results provide a reference for multiple types of research, including but not limited to: (1) estimating the economic burden of HPV-related diseases combined with the prevalence of these diseases; (2) conducting economic evaluation of HPV vaccination strategies in China or neighboring countries, combined with a transmission dynamics model; (3) evaluating the cost and affordability of combination strategies for the prevention and control of CC in China or neighboring countries; and (4) providing evidence to support the development of other related health policies.

\section{Acknowledgment}

We thank Liwen Bianji, Edanz Group China (www. liwenbianji.cn/ac), for editing the English text of a draft of this manuscript.

\section{Source of Funding}

WT acknowledges the support from Chinese National Natural Science Foundation (Grant No.: 71603278), Key Program of the National Natural Science Foundation of China (Grant No.: 71734003), and research project 
on postgraduate education reform under "double firstclass" capability construction from China Pharmaceutical University (Grant No.: 3151920118). LS is supported by a National Health and Medical Research Council Early Career Fellowship (Grant No.: GNT1139826). CM acknowledges the support from Chinese National Natural Science Foundation (Grant No.: 72074045).

\section{Conflict of Interest}

The authors declared there were no conflicts of interests. This work was not supported by the pharmaceutical industry or private funds. That said, Dr. Tang has received unrestricted institutional support from Chinese national science fund and China Pharmaceutical University.

\section{Author disclosures}

We confirm that this manuscript has not been published elsewhere and is not under consideration in whole or in part by another journal. All authors have approved the manuscript and agree with this submission.

\section{Author contributions}

WT takes responsibility for the integrity of the data and accuracy of the data analysis. Study design: YM, WD, and WT. Data analysis: YM and WD. Drafting of manuscript: YM and WD. Critical revision of the manuscript: CM, LS, $\mathrm{AM}$, and DM.

\section{REFERENCES}

1. Wang HQ, Wang Y, Wang CH, Wang YM, Sun XD, Xu DS, et al. Expert consensus on immunoprophylaxis of human papillomavirus-related diseases(abridged). Chinese Journal of Vaccines and Immunization 2019; 25:718-35. (In Chinese)

2. ICO/IARC Information Centre on HPV and Cancer (HPV Information Centre). Human Papillomavirus and Related Diseases in China. Summary Report 17 June 2019. Available from: https://hpvcentre.net/ index.php (Accessed Jan 19, 2020).

3. China National Cancer Center. 2018 China Cancer Registry Annual Report. Beijing: People Medical Publishing House, 2020. (In Chinese)

4. Yue XL, Gong XD, LI J, Teng F, Jiang N, Men PX, et al. Epidemiological features of condyloma acuminatum in national sexually transmitted disease surveillance sites in China from 2008 to 2016. Chinese Journal of Dermatology 2017; 50:321-5. (In Chinese)

5. Zhu J, Jin PM, Hua W, Chen J, Wu FQ, Li SP. Analysis of the Different Hospitalization Expenses of 15348 Cases of Cervical Malignant Tumor. Chinese Hospital Management 2017; 37:58-60. (In Chinese)

6. Wu SW, Chen T, Pan Q, Wei LY, Wang Q, Song JC, et al. Cost Analysis of Cervical Cancer Patients with Different Medical Payment Modes Based on Gamma Model within a Grade A Tertiary Hospital. Chin Med J (Engl) $2018 ; 131: 389-94$.

7. Lang HC, Wu SL. Lifetime costs of the top five cancers in Taiwan. Eur J Health Econ 2012; 13:347-53.

8. Hao XG, Feng XX. The Investigation and Analysis of 162 Cases in Condyloma Acuminate of Changzhi Area. Guide of China Medicine
2009; 7:38-40. (In Chinese)

9. Hu S, Xu X, Zhang Y, Liu Y, Yang C, Wang Y, et al. A nationwide postmarketing survey of knowledge, attitude and practice toward human papillomavirus vaccine in general population: Implications for vaccine roll-out in mainland China. Vaccine 2021; 39:35-44.

10. Wang Q, Zhang W, Cai H, Cao Y. Understanding the perceptions of Chinese women of the commercially available domestic and imported HPV vaccine: A semantic network analysis. Vaccine 2020; 38:8334-42.

11. World Health Organization. Electronic address: sageexecsec@who. int. Human papillomavirus vaccines: WHO position paper, May 2017-Recommendations. Vaccine 2017;35:5753-5.

12. Zhai L, Tumban E. Gardasil-9: A global survey of projected efficacy. Antiviral Res 2016; 130:101-9.

13. WHO. Draft global strategy towards the elimination of cervical cancer as a public health problem. Available from: https://www.who.int/docs/ default-source/cervical-cancer/cerv-cancer-elimn-strategyl6dec-12pm. pdf (Accessed Jan 28, 2020).

14. Levin CE, Sharma M, Olson Z, Verguet S, Shi JF, Wang SM, et al. An extended cost-effectiveness analysis of publicly financed HPV vaccination to prevent cervical cancer in China. Vaccine 2015; 33:2830-41.

15. Zhang Q, Liu YJ, Hu SY, Zhao FH. Estimating long-term clinical effectiveness and cost-effectiveness of HPV 16/18 vaccine in China. BMC Cancer 2016; 16:848.

16. Mo X, Gai TR, Wang L, Liu X, Wu B, Luo H, et al. Cost-effectiveness analysis of different types of human papillomavirus vaccination combined with a cervical cancer screening program in mainland China. BMC Infect Dis 2017; 17:502.

17. Chen ST, Zhou C, Chen Y. Economic burden of 184 patients with esophageal cancer in a tumor hospital. Jiangsu Health System Management 2020;31:1063-7.(In Chinese)

18. Costa AF, Ribeiro M, Onofre A, de Miranda OF. Aneuploidy detection for diagnostic and prognostic use in premalignant and malignant lesions of the uterine cervix: A systematic review. Diagn Cytopathol 2021; 49:33546.

19. Zhang Y, Wang J, Zhang R, Lei F, Lai S. Application Value of Detection of High-Risk HPV Infection in Early Cervical Cancer Patients in Disease Diagnosis and Prognosis Evaluation. Clin Lab 2020; 66. doi: 10.7754/ Clin.Lab.2020.200245.

20. Sopracordevole F, Clemente N, Di Giuseppe J, Barbero M, Fallani MG, Cattani P, et al. Clinical Characteristics and Long-Term Follow-up of Patients Treated for High-Grade Vaginal Intraepithelial Neoplasia: Results From a 20-Year Survey in Italy. J Low Genit Tract Dis 2020; 24:381-6.

21. Sak K. A Hypothetical Approach on Gender Differences in Cancer Diagnosis. J Transl Int Med 2019; 7:90-2.

22. Li S, Hu T, Lv W, Zhou H, Li X, Yang R, et al. Changes in prevalence and clinical characteristics of cervical cancer in the People's Republic of China: a study of 10,012 cases from a nationwide working group. Oncologist 2013; 18:1101-7.

23. Koh WJ, Abu-Rustum NR, Bean S, Bradley K, Campos SM, Cho KR, et al. Cervical Cancer, Version 3.2019, NCCN Clinical Practice Guidelines in Oncology. J Natl Compr Canc Netw 2019; 17:64-84.

24. Bhatla N, Denny L. FIGO Cancer Report 2018. Int J Gynaecol Obstet 2018; 143 Suppl 2:2-3.

25. Koh WJ, Greer BE, Abu-Rustum NR, Campos SM, Cho KR, Chon HS, et al. Vulvar Cancer, Version 1.2017, NCCN Clinical Practice Guidelines in Oncology. J Natl Compr Canc Netw 2017; 15:92-120.

26. NCCN Guidelines: Penile Cancer, Version 1.2016. Available from: https:// www.nccn.org/ (Accessed May 16, 2020).

27. Benson AB, Venook AP, Al-Hawary MM, Cederquist L, Chen YJ, Ciombor KK, et al. Anal Carcinoma, Version 2.2018, NCCN Clinical Practice Guidelines in Oncology. J Natl Compr Canc Netw 2018;16:852-71.

28. Pfister DG, Spencer S, Adelstein D, Adkins D, Anzai Y, Brizel DM, et al. Head and Neck Cancers, Version 2.2020, NCCN Clinical Practice 
Guidelines in Oncology. J Natl Compr Canc Netw 2020; 18:873-98.

29. Elbasha EH, Dasbach EJ, Insinga RP. A multi-type HPV transmission model. Bull Math Biol 2008; 70:2126-76.

30. Elbasha EH, Dasbach EJ. Impact of vaccinating boys and men against HPV in the United States. Vaccine 2010; 28(42):6858-67.

31. Ruthberg JS, Rasendran C, Kocharyan A, Mowry SE, Otteson TD. The economic burden of vertigo and dizziness in the United States. J Vestib Res 2021; 31:81-90.

32. Cai X, Yang H, Genchev GZ, Lu H, Yu G. Analysis of economic burden and its associated factors of twenty-three rare diseases in Shanghai. Orphanet J Rare Dis 2019; 14:233.

33. Mo X, Gai TR, Wang L, Liu X, Wu B, Luo H, et al. Cost-effectiveness analysis of different types of human papillomavirus vaccination combined with a cervical cancer screening program in mainland China. BMC Infect Dis 2017; 17:502.

34. Vorno T, Lutsar K, Uuskula A, Padrik L, Raud T, Reile R, et al. Costeffectiveness of HPV vaccination in the context of high cervical cancer incidence and low screening coverage. Vaccine 2017; 35:6329-35.

35. Myers ER, McCrory DC, Nanda K, Bastian L, Matchar DB. Mathematical model for the natural history of human papillomavirus infection and cervical carcinogenesis. Am J Epidemiol. 2000;151:1158-1171.

36. Ling XT, Peng YP, Lin ZQ. FIGO report on cancer in 2018-interpretation of thediagnosis and treatment of vaginal cancer. Chinese Journal of Practical Gynecology and Obstetrics 2019; 35:202-5. (In Chinese).

37. Fetters MD, Lieberman RW, Abrahamse PH, Sanghvi RV, Sonnad SS. Cost-effectiveness of pap smear screening for vaginal cancer after total hysterectomy for benign disease. J Low Genit Tract Dis. 2003;7:194-202.

38. Van Poppel H, Watkin NA, Osanto S, Moonen L, Horwich A, Kataja V. Penile cancer: ESMO Clinical Practice Guidelines for diagnosis, treatment and follow-up. Ann Oncol. 2013; Suppl 6:vi115-24.

39. Cromwell I, Gaudet M, Peacock SJ, Aquino-Parsons C. Cost-effectiveness analysis of anal cancer screening in women with cervical neoplasia in British Columbia, Canada. BMC Health Serv Res 2016; 16:206.

40. Benson AB, Venook AP, Al-Hawary MM, Cederquist L, Chen YJ, Ciombor KK, et al. Anal Carcinoma, Version 2.2018, NCCN Clinical Practice Guidelines in Oncology. J Natl Compr Canc Netw 2018; 16:85271.

41. Foster CC, Melotek JM, Brisson RJ, Seiwert TY, Cohen E, Stenson KM, et al. Definitive chemoradiation for locally-advanced oral cavity cancer: A 20-year experience. Oral Oncol 2018; 80:16-22.

42. Sher DJ, Tishler RB, Pham NL, Punglia RS. Cost-Effectiveness Analysis of Intensity Modulated Radiation Therapy Versus Proton Therapy for Oropharyngeal Squamous Cell Carcinoma. Int J Radiat Oncol Biol Phys 2018; 101:875-82.

43. Census Office of the State Council. Tabulation on the 2010 Population Census of the People's Republic of China. Beijing: China Statistics Press, 2012. (In Chinese)

44. Liu YJ, Keane A, Simms KT, Lew JB, Shi JF, Mazariego C, et al. Development and application of a framework to estimate health care costs in China: The cervical cancer example. PLoS One 2019; 14:e0222760.

45. State Administration of Foreign Exchange of China. 2020. Available from: http://www.safe.gov.cn/ (Accessed Dec 16, 2020). (In Chinese)

46. Liu GE, Hu SL, Wu JH, Dong ZH, Li HC. China Guidelines for Pharmacoeconomic Evaluations (2020). Beijing: China Market Press, 2020. Available from: https://tools.ispor.org/PEguidelines/source/ChinaGuidelines-for-Pharmacoeconomic-Evaluations-2020.pdf (Accessed May 16, 2020).

47. Lu Y, Li P, Luo G, Liu D, Zou H. Cancer attributable to human papillomavirus infection in China: Burden and trends. Cancer. 2020; 126:3719-32.

48. Rodriguez-Carunchio L, Soveral I, Steenbergen RD, Torne A, Martinez $\mathrm{S}$, Fuste $\mathrm{P}$, et al. HPV-negative carcinoma of the uterine cervix: a distinct type of cervical cancer with poor prognosis. BJOG 2015;122:119-27.
49. Li N, Franceschi S, Howell-Jones R, Snijders PJ, Clifford GM. Human papillomavirus type distribution in 30,848 invasive cervical cancers worldwide: Variation by geographical region, histological type and year of publication. Int J Cancer 2011;128:927-35.

50. De Sanjose S, Quint WG, Alemany L, Geraets DT, Klaustermeier JE, Lloveras B, et al. Human papillomavirus genotype attribution in invasive cervical cancer: a retrospective cross-sectional worldwide study. Lancet Oncol 2010; 11:1048-56.

51. Hu D, Goldie S. The economic burden of noncervical human papillomavirus disease in the United States. Am J Obstet Gynecol 2008; 198:500.e1-7.

52. Deshmukh AA, Zhao H, Franzini L, Lairson DR, Chiao EY, Das P, et al. Total Lifetime and Cancer-related Costs for Elderly Patients Diagnosed With Anal Cancer in the United States. Am J Clin Oncol 2018; 41:121-7.

53. Xu XQ, Rezhake R, Hu SY, Chen F, Zhang X, Pan QJ, et al. Effect of sequential rounds of cervical cancer screening on management of HPVpositive women: A 15-year population-based cohort study from China. Cancer Prev Res (Phila). 2021; 14:363-72.

54. Wang Z, Wang T, Yang J, Wang W, Zhang L, Su X, et al. Diagnostic Yield and Performance of a Large Population-Based Cervical Cancer Screening Program in High-Risk Rural China. J Cancer. 2020; 11:4000-6.

55. Ma L, Wang Y, Gao X, Dai Y, Zhang Y, Wang Z, et al. Economic evaluation of cervical cancer screening strategies in urban China. Chin J Cancer Res 2019; 31:974-83.

56. Lang HC, Wu SL. Lifetime costs of the top five cancers in Taiwan. Eur J Health Econ 2012; 13:347-53.

57. Canfell K, Shi JF, Lew JB, Walker R, Zhao FH, Simonella L, et al. Prevention of cervical cancer in rural China: evaluation of HPV vaccination and primary HPV screening strategies. Vaccine 2011; 29:2487-94.

58. Zou Z, Fairley CK, Ong JJ, Hocking J, Canfell K, Ma X, et al. Domestic $\mathrm{HPV}$ vaccine price and economic returns for cervical cancer prevention in China: a cost-effectiveness analysis. Lancet Glob Health 2020; 8:e133544.

59. Briggs AH, Weinstein MC, Fenwick EA, Karnon J, Sculpher MJ, Paltiel AD. Model parameter estimation and uncertainty: a report of the ISPORSMDM Modeling Good Research Practices Task Force--6. Value Health 2012; $15: 835-42$.

60. Song XB, Zhao QJ, Zhou Z, Fang Y. Health economic evaluation of bivalent human papilloma virus vaccine in China: based on the dynamic model. Zhonghua Yu Fang Yi Xue Za Zhi 2017; 51:814-20.

61. Ma X, Harripersaud K, Smith K, Fairley CK, Zou H, Zou Z, et al. Modeling the epidemiological impact and cost-effectiveness of a combined schoolgirl HPV vaccination and cervical cancer screening program among Chinese women. Hum Vaccin Immunother. 2021;17:1073-82.

62. Shiko Y, Konno R, Konishi H, Sauvaget C, Ohashi Y, Kakizoe T. Effectiveness of $\mathrm{HPV}$ vaccination against the development of high-grade cervical lesions in young Japanese women. BMC Infect Dis 2020; 20:808.

63. Mendes LW, Duarte FG, Burns JD, de Souza TSC, Chagas DAM, Reingold $A$, et al. Low coverage of HPV vaccination in the national immunization programme in Brazil: Parental vaccine refusal or barriers in healthservice based vaccine delivery? PLoS One 2018; 13:e0206726.

64. Wu S, Cui X, Zhang S, Tian W, Liu J, Wu Y, et al. Economic burden of readmission due to postoperative cerebrospinal fluid leak in Chinese patients. J Comp Eff Res 2020; 9:1105-15.

65. Chai Q, Shen Y, Du J, Zhu J, Wu B. Economic burden of patients with advanced non-small-cell lung cancer receiving nivolumab versus chemotherapy in China. Immunotherapy-UK 2020 ;12:245-54.

How to cite this article: Ding $\mathrm{W}, \mathrm{Ma} \mathrm{Y}, \mathrm{Ma}$ Ch, Malone DC, Ma A, Tang W, Si L. The lifetime cost estimation of human papillomavirusrelated diseases in China: a modeling study. J Transl Intern Med 2021; 9: $200-11$. 